\title{
Low Socio-Economic Level: A Major Obstacle to Therapeutic Observation (Survey of 125 Diabetic Patients)
}

\author{
Ousseynou Ka1*, Djiby Sow ${ }^{2}$, Elhadji Mouhamadou Seck², Ndeye Fatou Ngom Guéye ${ }^{3}$, \\ Martial Coly Bop', Mountaga Elimane Dia ${ }^{1}$, Abdoul Aziz Ndiaye1, Papa Gallo Sow ${ }^{1}$, \\ Maimouna Mbaye Ndour² \\ ${ }^{1}$ Community Health Department, Faculty of Health and Sustainable Development, Université Alioune Diop, Bambey, Senegal \\ ${ }^{2}$ Medical Clinic II, Centre Hospitalier Abass Ndao, Université Cheikh Anta Diop, Dakar, Senegal \\ ${ }^{3}$ Department of Medicine, Faculty of Health and Sustainable Development, Université Alioune Diop, Bambey, Senegal \\ Email: *ousseynou.ka@uadb.edu.sn
}

How to cite this paper: Ka, O., Sow, D., Seck, E.M., Guéye, N.F.N., Bop, M.C., Dia, M.E., Ndiaye, A.A., Sow, P.G. and Ndour, M.M. (2022) Low Socio-Economic Level: A Major Obstacle to Therapeutic Observation (Survey of 125 Diabetic Patients). Open Journal of Preventive Medicine, 12, 1-9. https://doi.org/10.4236/ojpm.2022.121001

Received: November 14, 2021

Accepted: January 21, 2022

Published: January 24, 2022

Copyright $\odot 2022$ by author(s) and Scientific Research Publishing Inc. This work is licensed under the Creative Commons Attribution International License (CC BY 4.0).

http://creativecommons.org/licenses/by/4.0/

(c) (i) Open Access

\begin{abstract}
Introduction: Diabetic patients adhering to their treatment are less likely to face complication from their disease. For this reason, we studied the compliance of diabetics with their treatment. Materials and Method: This was a comprehensive cross-sectional study of adherence in diabetic patients. All patients meeting the inclusion criteria were enrolled in the study. This study took place at a private pharmacy called "pharmacy Elhadj Seydou Nourou Tall" located in the city of Pikine during the period from April 1 to September 30, 2019. Results: In total, the study population was composed of $125 \mathrm{di}$ abetics; frequency of $8.47 \%$. The average age was 62.5 years and there were more women $(58.4 \%)$. Of the patients, $87 \%$ had a low socioeconomic level and $72 \%$ a low educational level. Only $65.6 \%$ of the patients knew their diabetes type. Even though $97.6 \%$ of the patients were confident in the treatment but due to financial reasons $20.8 \%$ did not adhere to the prescribed treatment and $16.8 \%$ to their diets. Moreover, $15.2 \%$ of the patients had changed the dosage of the prescribed medication, $44.4 \%$ had forgotten to take their medication regularly. $78.4 \%$ of them thought they were taking too much medication. No factors were found to be statistically associated with poor adherence, but the proportion of poor adherence patients was higher in patients over 60 years of age, with low socio-economic status and low education. Conclusion: Low socio-economic status is the main barrier to good adherence. Recommendations have been formulated to improve this adherence.
\end{abstract}

\section{Keywords}

Adherence, Diabetes, Socio-Economic Level, Barrier, Senegal 


\section{Introduction}

Diabetes is increasingly a major public health problem in Africa [1]. In Senegal, its prevalence according to the STEPS survey conducted in 2015 was $3.2 \%$ and this will increase in the coming years [2]. Considered as a chronic condition, the medical management of people with diabetes must be based on good therapeutic observance and good patient adherence. Adherence is defined as the degree of agreement between the patient's behaviour and the recommendations of the caregiver or therapist [3]. It is now well recognized that taking medications as prescribed and following therapeutic advice is essential for living with one's disease with a lower risk of worsening. Thus, improved adherence could have beneficial effects in reducing health care costs and improving the quality of life of patients with diabetes, particularly by reducing complications and hospitalizations. Furthermore, the WHO stated in 2003 that "improved adherence may have better health outcomes than the advent of new technologies" [4]. Nevertheless, the issue of adherence is complex, since many factors influence it and it is a dynamic process that evolves over time [5].

Adherence is therefore a major public health problem, since according to the World Health Organization (WHO), only 50\% of patients with chronic diseases are truly adherence. This figure is even lower in developing countries [4]. Studies on adherence among diabetics in Senegal are almost non-existent. Thus, this study could help determine the causes of non-adherence among diabetic patients and propose appropriate solutions.

It is for this reason that we initiated this study in order to assess the state of treatment adherence among diabetic patients who came to buy their medication at the Elhadj Seyd or Nourou Tall pharmacy in Pikine.

\section{Materials and Methods}

Study setting: The pharmacy is located in a district of the city of Pikine which is a department of the Dakar region. It is the only pharmacy in this area. This pharmacy is very popular with users. The staff includes a pharmacist, his assistant and three salesmen. Their role is to ensure the dispensing of medicines, provide advice on the proper use of medicines and ensure that the patient understands the treatment. Every year, the pharmacy participates in the celebration of the International Diabetes Day on November 14 by organizing free screening activities for the population. In addition, it is possible to do a blood sugar control every morning from 7:30 am at a cost of 1000 CFA francs (1.52 euro) per person. In case of high blood sugar, the user is referred to a health structure.

Type and period of study: This was a comprehensive cross-sectional descriptive and analytical study of diabetic adherence.

Adherence is the extent to which patients follow medical instructions, a kind of match between medical prescription and use. The World Health Organization proposes the following definition: "the extent to which a person's behaviour in taking a medicine, following a diet and/or making lifestyle changes corresponds 
to the recommendations agreed with a health professional" [3] [4].

Study period: It had lasted for six months from April 1, 2019 to September 30, 2019.

Selection of the study population: The study population consisted of diabetic patients who randomly came to the pharmacy to buy medicines. All patients who consented to participate in the study were included. The consent of these patients was obtained after explanation of the objectives of the study by the pharmacist. Indeed, these patients were reassured by the pharmacist since they were used to buy their medicines at the pharmacy. Moreover, there was a familiarity between the pharmacist and the patients.

Collection tools: The collection tool was a questionnaire designed by a team consisting of a public health physician, a diabetes physician and the pharmacist. The data were collected using this questionnaire which was pre-tested with 10 patients. After this test, the questionnaire was deemed reliable and validated. It included 17 items on medication adherence.

Data collection: The collection was done by a doctoral student in pharmacy who filled in the questionnaires himself.

Validity and reliability: The questionnaire targets patients with diabetes. In addition, the questions are translated into the local language for a better understanding.

Study variables: Data were collected on socio-professional characteristics (age, gender, occupation, economic level, education level...), on diabetes and on adherence to treatment...

The collection of these three elements makes it possible to assess the level of therapeutic adherence according to the socio-professional conditions of the patients but also according to the type of diabetes.

Data entry and analysis: The data was entered in Microsoft Office Excel software and analyzed by epi info 2000 version 3.3.2 software. In the analysis a descriptive and analytical study was done. A comparison of the level of therapeutic adherence was made according to the socio-economic conditions of the patients but also according to the type of diabetes.

Ethical considerations: Permission was obtained from the pharmacy manager. Data were collected anonymously and kept confidential.

\section{Results}

The number of patients was 1475. Among these patients, one hundred and twenty-five (125) diabetics had agreed to participate voluntarily in the study, frequency of $8.47 \%$.

Age: The mean age was 62.5 years with extremes ranging from 18 to 72 years. The age group [50 - 65] years was the most represented with $48 \%$ followed by [25 - 49] with $38.4 \%$.

Gender: There were more women $(58.4 \%)$ than men $(41.6 \%)$ for a sex ratio of 0.71 . 
Profession: Shopkeepers were the most represented (30.4\%), followed by housewives (26.4\%) and pensioners (9.6\%). The majority of patients (87\%) worked in the informal sector.

Socio-economic level: The economic level was low since the income of the majority of patients (87\%) was well below the minimum wage [6] and sometimes even absent.

Educational level: The level of formal education was low as the majority of patients $(72 \%)$ had no more than primary education.

Type of diabetes: Only $65.6 \%$ of the patients knew their type of diabetes and among them $86.6 \%$ had type 2 diabetes and $13.4 \%$ had type 1 diabetes. On the other hand $34.4 \%$ of the patients could not determine their type of diabetes.

Diabetes monitoring: Just under $1 / 4$ of patients (24\%) were not monitoring their blood glucose levels as they did not have a glucose meter.

Confidence in treatment: Almost all patients (97.6\%) had confidence in the prescribed treatment.

Adherence: A significant number of patients (20\%) did not comply with the prescribed treatment for financial reasons.

Dietary adherence: Of the patients, $16.8 \%$ did not comply with their diets for financial reasons.

Change in dosage: $15.2 \%$ of the patients had changed the dosage of their prescribed medication because they felt they were taking too much medication or sometimes for financial reasons.

Renewal of medicines: A significant number of patients (20.8\%) did not regularly refill their medicines due to financial reasons; they claimed that medicines were expensive.

Perception of the number of medications to be taken: $78.4 \%$ of the patients thought they were taking too many medications.

Mode of treatment: Monotherapy was noted in $57.6 \%$ of patients, dual therapy in $34.4 \%$ and triple therapy was $8 \%$.

Drug families: The main drugs prescribed were biguanides (53.2\%), followed by insulin (25.4\%) and finally sulphonamides (21.4\%).

Forgetting to take medication: Among the patients, $44.4 \%$ had forgotten to take their medication regularly. This forgetfulness concerned particularly the midday dose but also the evening dose.

Proportion of diabetics with high blood pressure: High blood pressure was found in $40 \%$ of diabetic patients. Indeed, diabetes and hypertension have the same risk factors and their association is frequent.

Analytically: No factors were found to be statistically associated with poor adherence, but the number of poorly adherence patients was higher in patients over 60 years of age (20 versus 15), in patients with a low economic level (32 versus 3 ), and in patients with little education (28 versus 7 ).

\section{Discussion}

Type of diabetes: Only $65.6 \%$ of the patients knew their type of diabetes and 
among them $86.6 \%$ had type 2 diabetes and $13.4 \%$ had type 1 diabetes. On the other hand $34.4 \%$ of the patients could not determine their diabetes type. In the study by Owodele et al. [7], type II diabetes accounted for $89.5 \%$ of diabetics. As elsewhere, type II diabetes constituted $70 \%-85 \%$ of diabetics [8]. This result can be explained by the progression of diabetes in Senegal, linked to factors such as the increase in sedentary lifestyle, obesity, increased life expectancy, growing urbanization, and also the more active screening of the disease.

Signs of hyperglycemia: In our study, $31.2 \%$ of the patients did not know the symptoms of hyperglycemia. In a study conducted in Kinshasa, $66.2 \%$ of patients had a low level of knowledge of the symptoms [9]. These authors explained that this weakness would be due partly to the low level of education but also to the absence of therapeutic education.

Glycemic monitoring: $24 \%$ of the patients did not monitor their blood glucose levels because they did not have glucometers. In the Diabcare and Koné F studies, the proportion of diabetic patients with glucometers was $30 \%$ and $20.5 \%$ respectively [10] [11]. Patients who did not have glucometers felt that they could not afford them. However, good glycemic control of diabetes is recommended to prevent the occurrence or delay the progression of complications, particularly cardiovascular ones. Monitoring of blood glucose control should be based on HbA1c testing every 3 months, ideally in the same laboratory.

Adherence: Although almost all patients (97.6\%) trusted the prescribed treatment, almost $1 / 4$ of them (20.8\%) did not comply with it as they did not renew their medication. The financial problem was the major obstacle. In Senegal, a study estimated the average monthly cost of treatment for oral antidiabetic drugs at 918,339 f CFA (14€) excluding indirect expenses related to diabetes [12] while the SMIG (guaranteed interprofessional minimum wage) is only 45,000 $\mathrm{f}$ CFA (79€) [6]. Moreover, our patients, most of whom come from the informal sector, had no social security coverage. Thus, faced with the difficulty of renewing medicines, patients may often resort to traditional medicine or even abandon the treatment, increasing the risk of complications [13]. However, the main drugs listed in our study such as biguanides (53.2\%), insulin (25.4\%), and sulfonamides $(21.4 \%)$ are on the national list of essential drugs where their cost is accessible. But unfortunately, these drugs are often in short supply in health facilities. And in case of shortage, diabetic patients turn to pharmacies to obtain these "specialty drugs" where they are more expensive (source of therapeutic non-adherence). In Ivory Coast, Ankotche et al. estimated this cost at 70\% - 96\% of the family income for the poorest patients, compared to $25 \%$ - $55 \%$ for patients with intermediate resources, not taking into account hospitalization costs and those arising from diabetic complications [14].

Authors have shown that $50 \%$ of diabetic patients do not take their oral antidiabetics correctly, 9\% never take anything, 36\% take insufficient doses [14] [15].

Evaluation of the frequency of forgetfulness: Among our patients, $44.4 \%$ 
had often forgotten to take their medicines and this forgetfulness is mostly about taking lunch [16]. This situation can be explained by the fact that the vast majority of our patients are from the informal sector. They leave their homes in the morning and only return in the evening, more concerned with finding daily expenses to support the family.

Number of drugs taken: In our study, 78.4\% ( $\mathrm{n}=98)$ of the patients thought that they had taken too many drugs. Our result was higher than that of Kone $\mathrm{F}$ [11] estimated at $48 \%$. A patient who feels that he/she is taking too many drugs may be tempted to eliminate some of them. Thus, adherence is dependent on the number of tablets to be taken per day since it is $88 \%$ for one tablet per day and $39 \%$ for four tablets per day [17].

Side effects are sometimes a reason for discontinuing treatment, especially if they are significant, annoying or even unbearable. According to the study by Grant et al. [18] of 128 diabetic patients, side effects of a drug were a reason for discontinuing treatment.

Non-adherence with medication decreases in the elderly due to multiple medications linked to multiple pathologies with the risk of iatrogenic pathologies. According to a Tunisian study in 2009 [19], patients with poor adherence were older. Similarly, in 2013 Guénette L. et al. [15] found that people aged over 54 years were less adherence than those aged between 18 and 53 years.

In our study, $15.2 \%$ of the patients had changed the dosage of the prescribed medication. In fact, a patient who thinks he is taking a lot of medication voluntarily reduces the dosage. The same is true in case of side effects. Faced with these situations, it happens that the patient abandons this treatment especially if he does not feel any more symptoms "believing himself cured". In any case, an insufficient dosage has no therapeutic effect and favours the occurrence of complications.

Dietary modification: Dietary modification was noted in $16.8 \%$ of patients. Follow-up of the diet is very important in diabetic patients. In the study by Koné F. 72\% said they followed the dietary prescriptions correctly [11]. This finding can be explained by financial and socio-cultural constraints. In addition, diabetic patients always want to eat with their families where there is more conviviality. Eating alone is stigmatizing. The results of Gning SB et al. suggest a socioeconomic context that is not conducive to a diabetic diet [12].

Physical activity: Physical activity was noted in $56 \%$ of patients. In Mali, Guillaume K T [20] found in his study that $73.3 \%$ of patients practiced physical activity and $54.5 \%$ had started before the discovery of their diabetes. The practice of physical activity is recommended in particular for diabetic patients because of the beneficial effects on the balance of diabetes, thus constituting an important element in the arsenal of therapeutic management of diabetics.

\section{Limitations of the Study}

This is a piecemeal study of diabetic patients living in urban areas. These patients are able to access health structures whereas the majority of diabetic pa- 
tients experience difficulties in accessing health care. The number of diabetic patients is limited.

It is important to do a study integrating diabetics from different localities of the country.

\section{Conclusions}

Therapeutic adherence is a major challenge in the fight against diabetes and therefore other chronic diseases. It is not enough for the health care provider to issue a medical prescription, but it must be respected by the patient. The observed factors of non-adherence are medical and non-medical, hence the interest of a good coordination between the patient, the attending physician, the nursing staff and the family environment. The following recommendations have been formulated:

To the health authorities: Extend the list of essential drugs to include in medicines required for the treatment of diabetes by ensuring their availability in appropriate galenic forms and dosages.

Health care personnel: Integrate therapeutic education and psychological support into diabetes care management; train pharmacy personnel on therapeutic adherence.

To the diabetic population: To assist the elderly people to respect the prescribed treatment; to encourage people with diabetes to join the mutual health insurance.

\section{Acknowledgements}

We also thank the members of the UADB "health and nutrition" research team and "Health and Transitions in Africa" from UMI 3189 "Environment, Health and Societies".

\section{Authors' Contributions}

All authors contributed equally to this work.

\section{Conflicts of Interest}

The authors declare no conflicts of interest.

\section{References}

[1] IDF (2019) The IDF Diabetes Atlas. 9th Edition. https://diabetesatlas.org/atlas/ninth-edition/

[2] https://www.who.int/ncds/surveillance/steps/Senegal_2015_STEPS_FS.pdf

[3] Sabaté, E. (2001) Non Communicable Diseases and Mental Health Cluster. Adherence to Long-Term Therapies: Policy for Action: World Health Organization; Meeting Report, 4-5 June 2001. https://apps.who.int/iris/handle/10665/66984

[4] World Health Organization (2003) Adherence to Long-Term Therapies: Evidence for Action. https://apps.who.int/iris/handle/10665/42682

[5] Reach, G. (2008) Patient Non-Adherence and Healthcare-Provider Inertia Are 
Clinical Myopia. Diabetes \& Metabolism, 34, 382-385.

https://doi.org/10.1016/j.diabet.2008.02.008

https://pubmed.ncbi.nlm.nih.gov/18706843

[6] https://votresalaire.org/senegal/salaire

[7] Awodele, O. and Osuolale, J.A. (2015) Medication Adherence in Type 2 Diabetes Patients: Study of Patients in Alimosho General Hospital, Igando, Lagos, Nigeria. African Health Sciences, 15, 513-522. https://doi.org/10.4314/ahs.v15i2.26

[8] Osei, K., Schuster, D.P., Amoah, A.G. and Owusu, S.K. (2003) Diabetes in Africa. Pathogenesis of Type 1 and Type 2 Diabetes Mellitus in Sub-Saharan Africa: Implications for Transient Populations. Journal of Cardiovascular Risk, 10, 85-96. https://doi.org/10.1177/174182670301000203

[9] Kennedy, M., Mala, A.M., Paulin, B.M. and Muyer, M.C. (2014) A Case-Control Study to Determine the Sources of Nonadherence to Medical Monitoring in Diabetic Patients in Kinshasa in 2010. The Pan African Medical Journal, 17, 258. https://www.ncbi.nlm.nih.gov/labs/pmc/articles/PMC4189857

[10] Mbaye, M.N., Niang, K. and Sarr, A. (2011) Epidemiological Aspects of Diabetes in Senegal: Results of a Survey on Cardiovascular Risk Factors in the City of Saint-Louis. Medicine of Metabolic Diseases, 5, 659-664.

[11] Kone, F. (2014) Evaluation of the Difficulties Related to the Follow-Up and Management of Diabetes in Senegal: A Survey Conducted at the Marc Sankalé Centre in Dakar. Cheikh Anta Diop University, Dakar, No. 22.

[12] Gning, S.B., Thiam, M., Fall, F., Fall, K.B. and Mbaye, P.S. (2007) Diabetes Mellitus in Sub-Saharan Africa, Epidemiological Aspects Management Difficulties. Medecine Tropicale, 67, 607-611. https://bdsp-ehesp.inist.fr/vibad/index.php?action=getRecordDetail\&idt=378014

[13] Ka, O., Mbaye, E.H., Leye, M.M.M., Faye, A., Tall, A.B., Gaye, A., et al. (2016) Plan Sésame in Senegal: Limits of This Free-of-Charge Model. Public Health, 1, 91-101. https://www.cairn.info/revue-sante-publique-2016-1-page-91.htm https://doi.org/10.3917/spub.161.0091

[14] Ankotche, A., Binan, Y., Leye, A., Biekre, A.R., Adoueni, V., Toutou, T. and Loukrou, A. (2009) Serious Consequences of the Financial Cost of Diabetes on Its Management, Apart from Complications, in Sub-Saharan Africa: The Example of Côte d'Ivoire. Médecine des maladies Métaboliques, 3, 100-105. https://doi.org/10.1016/S1957-2557(09)70126-9

[15] Guenette, L., Moisan, J., Breton, B. and Sirois, C. (2013) Difficulty Adhering to Antidiabetic Treatment: Factors Associated with Persistence and Adherence. Diabetes \& Metabolism, 39, 250-257. https://doi.org/10.1016/j.diabet.2012.12.005

[16] Chambonet, J.Y. and Broard, F. (2001) Are You Forgetting Your Meds? Médical Concours, 32, 2159-2163.

[17] Bagonza, J., Rutebember, E. and Bazeyo, W. (2015) Adherence to Anti Diabetic Medication among Patients with Diabetes in Eastern Uganda; a Cross Sectional Study. BMC Health Services Research, 19, Article No. 168. https://doi.org/10.1186/s12913-015-0820-5

[18] Grant, R.W., Devita, N.G., Singer, D.E. and Meigs, J.B. (2003) Polypharmacy and Medication Adherence in Patients with Type 2 Diabetes. Diabetes Care, 26, 1408-1412. https://pubmed.ncbi.nlm.nih.gov/12716797 https://doi.org/10.2337/diacare.26.5.1408

[19] Chakroun, E., Ben Salem Hachmi, L., Bouzid, C., Kammoun, I., Maatki, C., Turki, Z. and Ben Slama, C. (2009) Influence of Socioeconomic and Educational Level on 
Adherence in Type 2 Diabetics. Diabetes \& Metabolism, 35, 67.

https://www.em-consulte.com/article/203889/p164-influence-du-niveau-sociohecon omique-et-du-ni

https://doi.org/10.1016/S1262-3636(09)71962-7

[20] Guillaume, K.T. (2010) Knowledge and Practical Attitudes of Diabetics on Physical activity. Thesis, Mali. 